\title{
SELF-PERCEIVED INTEGRATION OF IMMIGRANTS AND THEIR CHILDREN ${ }^{1}$
}

\author{
ZHENG Wu \\ Christoph M. Schimmele \\ FENG Hou
}

\begin{abstract}
The purpose of this study is to examine the relationship between immigrant generation and subjective well-being. The study disaggregates the immigrant population into first, 1.5, second, and higher order "generations" and compares their prospects for social integration. The study focuses on two aspects of integration: sense of belonging to Canada and feelings of discomfort living in the host society. The analysis also addresses whether the effects of immigrant generation on integration are conditional on the context of settlement, including racial status and neighbourhood environment. The study merges data from the 2001 Canadian Census and the postcensus Ethnic Diversity Survey. The primary conclusion is that the relationship between immigrant generation and integration is complex. The findings demonstrate the need to use a fine-grained approach for understanding the integration of immigrants and their children.
\end{abstract}

Key words: immigrants, immigrant generation, integration, assimilation, neighbourhood effects

Résumé. Le but de cette étude consiste à examiner la relation entre génération immigrante et bien-être subjectif. L'étude subdivise la population immigrante en première génération, en première génération et demie, en deuxième génération et en génération supérieure et compare leurs chances d'intégration sociale. L'étude cible deux aspects d'intégration, c'est-à-dire le sens d'appartenance au Canada et le sentiment de malaise de vivre dans la société d'accueil. L'analyse aborde également la question de savoir si l'effet de la génération immigrante sur l'intégration dépend du contexte dans lequel l'établissement se fait, incluant le statut racial et le quartier. L'étude fusionne les données du recensement canadien de 2001 et l'Enquête sur la diversité ethnique qui a eu lieu après le recensement. La grande conclusion à tirer de cette étude et le fait que la relation entre la gé-

1. Financial support from a Metropolis British Columbia grant awarded to the first author is gratefully acknowledged. An early version of this paper was presented at the annual meetings of the Canadian Population Society, Montreal, May 31-June 3, 2010. Direct all correspondence to Zheng Wu, Department of Sociology, University of Victoria, Victoria, BC, V8W 3P5 Canada. 
nération immigrante et l'intégration est complexe. Les conclusions démontrent le besoin d'utiliser une approche fine pour comprendre l'intégration des immigrants et de leurs enfants.

Mots clés : immigrants, génération immigrante, assimilation, effet du quartier

\section{INTRODUCTION}

rior studies on the integration of immigrants and their children have focused largely on their socioeconomic mobility, language use, residential segregation, intermarriage, and other external criteria of well-being (Houle and Schellenberg 2010; Waters and Jiménez 2005). This study contributes to the literature through an examination of self-perceived integration. The objective is to determine whether sense of belonging to Canada and feelings of discomfort living in the host society differs across generational cohorts of immigrants. The question "Do I belong?" is, perhaps, a sharper and more pervasive consideration for immigrants than the Canadian-born, especially among racial minorities. The answer to this question depends a lot on the extent to which immigrants perceive Canada as "home" and also their perceptions of inclusion (or exclusion) within their host society.

This study disaggregates the immigrant population into first generation, 1.5 generation, and second generation immigrants. However, a fine-grained analysis of immigrants cannot stop here. The process of integration also depends on the ethno-racial background of immigrants and the structural characteristics of their settlement environments. Racial discrimination and residential concentration (e.g., segregation) are major constraints on the integration of immigrants. Studies on the socalled "new immigration" question whether the previous pathways of immigrant adaptation/integration remain viable, given the shifts in the demographic composition of immigration streams after immigration reform and the settlement patterns of recent immigrants (see Alba and Nee 1997; Gans 1992; Portes and Zhou 1993). These contextual conditions are fundamental to the settlement experience.

While integration could be conditional on generational status, we cannot assume that these intergenerational effects are the same across different groups of immigrants and social environments. A better assumption is that both ethno-racial status and neighbourhood context confound or influence the relationship between immigrant generation and social integration. The main questions are whether being a racial minority or living in a neighbourhood with a high concentration of coethnics are constraints on social integration and whether these conditions have an influence on intergenerational progress or decline. To address 
these questions, this study uses multilevel models, which are suitable for assessing contextual effects, and focuses on urban Canadian neighbourhoods. Since the 1970s, Canada has become increasingly diverse through immigration from non-European countries, and multiculturalism has been an official policy of the federal government since 1982 . This makes Canada an ideal setting for observing the integration of immigrants.

\section{Conceptual Background}

Few Canadian studies have addressed the subjective well-being of immigrants and their children. What is known, however, demonstrates the importance of considering subjective assessments of their settlement experience. What is troubling is that both adult and young immigrants report lower levels of life satisfaction than their Canadian-born counterparts, and this associates with their socioeconomic and ethno-racial status (Burton and Phipps 2010). Their life satisfaction, moreover, does not appear to be related to years since arrival in Canada, which implies that immigrants encounter long-term barriers to subjective well-being. The perception of acceptance (or discrimination) in the host society is a salient aspect of the life satisfaction of immigrants (Houle and Schellenberg 2010). Having social ties (e.g., good perceptions of neighbours) increases their life satisfaction. In contrast, the experience of discrimination has a well-observed negative effect on their life satisfaction, and it also can disrupt their adaptation to the host society (Chow 2007; Vohra and Adair 2000). The problems that hinder life satisfaction among immigrants tend to kindle regrets about their decision to immigrate to Canada (Houle and Schellenberg 2010).

This study expands on our knowledge of the subjective well-being of immigrants with an examination of two interrelated outcomes: (a) sense of belonging to Canada and (b) feelings of discomfort living in the host society. In this study, the social integration of immigrants refers to the extent to which these people form primary relations with the host society (Reitz and Banerjee 2007). An immigrant's sense of belonging is a reflection of integration into social networks and institutions, and it fosters feelings of social solidarity with the core or socially predominant group (Schellenberg 2004). For immigrants, a sense of belonging is a source of well-being, and it is also a factor in their long-term commitment to Canada (Chow 2007). In broad terms, it embodies whether or not an immigrant feels welcome, secure, and "at home" in Canadian society (Soroka et al. 2007; Wu et al. 2011). Feelings of discomfort living in the host 
society are incompatible with a sense of belonging. ${ }^{2}$ The feeling of discomfort is analogous to the perception of exclusion or marginalization, because the latter inhibits both social and civil participation (Reitz and Banerjee 2009). In this respect, feelings of discomfort are a proxy for the perceived social distance between immigrants and the Canadian-born.

\section{Social Integration and Immigrant Generation}

The social and economic integration of immigrants tends to be conceptualized as an intergenerational process. In the classic model, the integration of immigrants and their children progresses with length of residence in the receiving population and, more prominently, across generations (Alba and Nee 1997; Gordon 1964; Hirschman 1994). With each successive generation, the descendants of first generation immigrants become less distinguishable from the mainstream in regards to their socioeconomic status, social networks, and attitudes. This process culminates with what Milton Gordon (1964) termed structural assimilation or the stage of integration when the children (or grandchildren) of immigrants resemble the core group in their social relations and institutional affiliations. ${ }^{3}$ This stage of integration has a high level of self-identification as belonging to the core group (e.g., being Canadian) and strong primary relations in the host society.

To be sure, such intergenerational progress appears to be specific to white immigrants and/or particular historical circumstances (Gans 1992; Portes and Zhou 1994; Rumbaut 1994). But the concept of generational cohorts is still germane to both the classic model of integration and its alternatives. Whether the outcome is second generation progress or decline, this involves a process of intergenerational change. The overarching question remains whether to count the foreign-born children of immigrants as members of the first generation, the second genera-

2. In unreported analysis, we observed a significant relationship between sense of belonging to Canada and feeling uncomfortable or out of place in the host society $(r=-0.12, p$ $<0.001$ ). This confirms that sense of belonging to Canada decreases as the level of feeling uncomfortable in the host society because of racial status or religious background increases. In other words, there is a correlation between sense of belonging to Canada and feeling uncomfortable in the host society.

3. At present, there is a minor difference between how the concept of assimilation is employed in US studies and how the concept of integration is employed in Canadian/ European studies (Vermeulen 2010). Like integration, assimilation tends to refer to a process of mutual adaptation and accommodation. In Milton Gordon's (1964) classic definition, structural assimilation involves the full incorporation of immigrants into mainstream social networks and institutions. This does not correspond to the loss or relinquishment of an immigrant's cultural traits, language, or tastes (Deng and Walker 2007). As Gans (1997) observes, immigrant assimilation is compatible with the retention of ethnic or cultural identity (e.g., being Chinese-Canadian) and thus does not preclude cultural pluralism. 
tion, or something more refined. The literature on "decimal generations" demonstrates the importance of using a fine-grained definition. Previous research shows that there are conceptual and empirical reasons for disaggregating immigrants and their children into generational cohorts, such as adult immigrants (the first generation), foreign-born child immigrants (the 1.5 generation), and native-born children of immigrants (the second generation) (e.g., Böhlmark 2009; Lee and Boyd 2008; Oropesa and Landale 1997; Rumbaut 2004; Thomas 2010).

To some degree, all foreign-born people have been socialized in foreign countries. These social differences are precisely what raise the problem of social integration in the first place. The challenges of settling in a new cultural and socioeconomic environment are clear from research indicating that the process of adaptation can lead to acculturative stress in some instances (see Berry et al. 1987). Moreover, negotiating an unfamiliar environment, feeling like a cultural outsider, and encountering discrimination are, presumably, barriers to perceptions of belonging or feeling comfortable in the host society. The process of adaptation and the barriers to integration are inseparable from life stage at immigration (Rumbaut 2004). This determines where and how immigrants were socialized, i.e., their identities and sociocultural difference vis-à-vis the core group. In addition, it affects their retention of premigration cultural traits and attitudes and attachment to place of origin.

Adult immigrants are not expected to achieve full integration because their newcomer/foreigner status has long-term implications for their social adaptation and acceptance (Hirschman 1994; Rumbaut 2004). Adult immigrants are unlikely (or at least less likely) to abandon their native languages, cultural roots, and ethnic identities in the process of adaptation. The retention of premigration cultural habits, social ties, and national loyalties could represent a form of social distance between themselves and the native-born. The comparative lack of social integration among first generation immigrants is reflected in the endogeneity of their social networks. First generation immigrants have fewer cross-ethnic social ties and lower rates of intermarriage than child immigrants and the native-born population (Brown 2006; Lee and Boyd 2008; Pagnini and Morgan 1990). What this implies for integration is unknown, but it is not unreasonable to assume that the nature of an immigrant's social relationships, ethnic identities, and transnational attachments could affect her/ his perceptions of belonging and feelings of discomfort living in the host society.

Preadolescence is a crucial life stage in the immigration experience because child immigrants have limited choice in the decision to immigrate and also encounter unique age-related problems in the adaptation 
process (Bartley and Spoonley 2008; Rumbaut 2004). The foreign-born children of immigrants are a "special class" of migrants referred to as the 1.5 generation (Bartley and Spoonley 2008). The 1.5 generation represents a generational cohort that is "in-between" sociocultural environments and identities. The literature documents that the 1.5 generation possesses an awareness of being neither from "here" (the receiving population) nor "there" (the sending population) because of their transnational socialization and their struggle with dual identities (Bartley and Spoonley 2008; Danico 2004; Kong 1999). While being immigrants, the 1.5 generation comes of age in the host population and draws from different sets of cultural values. This bicultural experience creates a unique problem for their mode of acculturation: a potentially simultaneous (competing) pull of their place of origin and place of settlement on their sense of belonging that neither the first nor second generations confront (Bartley and Spoonley 2008).

Though not immigrants themselves, the second generation are raised in immigrant-headed households, which represents a contextual factor that could influence their social integration. The second generation is, essentially, Canadian at birth, and from birth is exposed to the mainstream culture. Unlike their parents, this generation does not have to struggle with language barriers or negotiate unfamiliar cultural norms. However, this generation is also socialized in immigrant-headed households and, perhaps, also within ethnic minority communities (Hirschman 1994). The assumption is that, to some degree, children align themselves at the household level. The question here is whether, and to what extent, national loyalties are transmitted from the first to the second generation (Rumbaut 2004). The household is an important context for sense of belonging among the second generation. The experiences of this generation's parents (e.g., discrimination) are a barometer of their expectations. In certain cases, these experiences can sustain ethnic or pan-ethnic identities across generations as a reaction to exclusion from the mainstream. This leads us beyond the independent effects of generational status and to its intersection with ethno-racial status.

\section{The Effect of Ethno-racial Status}

The effect of immigrant generation on integration is entangled with racial status. The intergenerational incorporation of immigrants depends on the context of their reception (Rumbaut 1994). The straight-line model assumes that the children of immigrants will be accepted into their host communities, with the gradual erosion of social boundaries and corresponding forms of discrimination. However, there appears to 
be a colour barrier to integration, and thus the potential for segmented or "downward assimilation" among the new second generation, whose parents immigrated from Asia, Africa, and other non-European regions (Gans 1992; Portes and Zhou 1993; Rumbaut 1994). In Canada, generational cohorts of immigrants have different racial compositions. For example, most racial minorities (about two-thirds) are first generation immigrants (Statistics Canada 2003). In contrast, few racial minorities are third generation Canadians. ${ }^{4}$ Hence, it is crucial to disentangle the effects of generational status from the effects of racial status.

The new immigration has transformed Canada's ethno-cultural mosaic, re-raising questions about the integration of immigrants (Lee and Boyd 2008). The integration of immigrants has indeed become more irregular because of their non-European origins (Banting et al. 2007). The integration of immigrants could follow several different trajectories depending on household resources, socioeconomic conditions, and local context (Rumbaut 1994). The chief concern is that the immigrants, especially the new second generation, could be incorporated into a racial underclass because of discrimination and limited opportunities for socioeconomic mobility (Gans 1992). In Canada, racial inequalities, particularly those that affect household income and low-income rates, are a growing problem. In 2002, the mean household income of racial minorities was $23 \%$ lower than the national average and their low-income rate was double that of whites (Reitz and Banerjee 2009). Furthermore, feelings of discomfort living in Canadian society and discrimination are common among racial minorities (Ray and Preston 2009). In 2002, about one in five racial minorities reported experiencing discrimination or unfair treatment (Statistics Canada 2003).

Although measured as an individual-level variable, racial status is, in essence, a contextual (social structural) variable (Portes and Zhou 1993). In this case "who you are" is an ascribed status that reflects the predominant attitudes in the host society. The integration of immigrants is a twosided process that involves both adaptation and accommodation. A potential barrier to integration is an unreceptive host population. Rumbaut (1994) demonstrates that immigrants can retreat from self-identification as American, opting instead for non-American nationalities (e.g., Mexican) or pan-ethnic (e.g., Hispanic) identities in reaction to marginalization or exclusion. People who feel excluded from the mainstream have fewer incentives to invest themselves in collective enterprises or form

4. About $45 \%$ of first generation Canadians arrived after 1991, coming largely from nonEuropean countries (Statistics Canada 2007). In total, ethno-racial minorities compose about $53 \%$ of first generation, $14 \%$ of second generation, and under $1 \%$ of third or higher generation. 
ties with the core group (Reitz and Banerjee 2009). Racial discrimination can compel visible minorities to disengage from or even reject the mainstream. In other words, a sense of alienation among nonwhite immigrants could have a negative effect on their integration.

\section{The Effect of Residential Concentration}

A principal feature of the new immigration is the uneven regional dispersion of immigrants and their concentration in urban areas (Alba and Nee 1997). For several reasons, where immigrants settle is not inconsequential for their integration. First, neighbourhood characteristics shape the opportunities and life chances of their residents, regardless of individual differences in socioeconomic status (see Sampson et al. 2002). Second, neighbourhoods provide an important context for social interactions. For example, mixed-race neighbourhoods provide the potential for crosscultural interactions that can breakdown racial stereotypes and prejudice (Fong and Wilkes 2003). This contact can forge social ties between different groups that lead to acceptance and integration. Third, the concentration of immigrants in poor neighbourhoods could have serious consequences for their integration. A breakdown of social institutions and social cohesion is not uncommon in poor neighbourhoods (Massey 1990; Sampson et al. 2002). This breakdown, in conjunction with a pervasive lack of educational and employment opportunities, can have consequences that inhibit social integration.

The long-standing assumption is that spatial assimilation is an indicator of the integration of immigrants. In the classic model, spatial assimilation is considered a marker of immigrant socioeconomic success and integration into host communities. The spatial assimilation model posits that segregation is a function of group differences in socioeconomic status (Massey 1985). Since numerous immigrants enter host communities with limited socioeconomic resources, they move into neighbourhoods with cheap housing and co-ethnic social networks. With socioeconomic success and length of residence (and across generations), immigrants relocate to neighbourhoods with better housing and amenities, which implies greater co-residence and social interaction with members of the core group. However, because of racial discrimination in housing markets, not all immigrants can convert socioeconomic success into residential mobility (Hou 2006; Massey and Denton 1987).

There is debate over whether the residential concentration of coethnics is indeed a barrier to integration (Bolt et al. 2010; Murdie and Ghosh 2010; Musterd 2003). The assumptions about the relationship between residential concentration and integration are largely based on the 
US experience, which represents a social and racial context that might not be germane to Canada or other countries (Boyd 2002). The question for debate is whether the residential concentration of ethnic/racial groups represents a form of social isolation (segregation) from the mainstream or self-selection in neighbourhood preferences. Although the pervasive view is that residential concentration goes hand-in-hand with deprivation and exclusion, others consider it as a neutral concept and not necessarily linked to integration (Bolt et al. 2010). Of course, it is possible that residential concentration represents social distance between immigrants and non-immigrants, especially across racial boundaries. However, the residential concentration of immigrants need not involve a lack of integration. For example, immigrants come into regular contact with non-immigrants outside their neighbourhoods, such as in public spaces, schools, and workplaces.

\section{Data And Methods}

\section{Data Sources}

The study uses cross-sectional data from the 2002 Ethnic Diversity Survey (EDS) and the 2001 Canadian Census. The individual-level data are from the EDS. The EDS was designed to collect data on the ethno-cultural backgrounds of Canadians and their participation in various aspects of social life and the economy (Statistics Canada 2003).The EDS is a postcensal survey and the respondents were selected from those who completed the long form of the 2001 Census (one in five households). The long-form questionnaire contains questions about country of birth, date of immigration, parent's country of birth, ancestral background, and other sociodemographic characteristics. This permits the identification of first generation, 1.5 generation, second generation, and third or higher generation Canadians (Aydemir et al. 2008). The EDS is a nationally representative sample of over 42,000 Canadians aged 15 years and older in all ten provinces. ${ }^{5}$ The EDS oversampled people of non-European ancestry to facilitate the analysis of ethnic/racial minorities. Further details on the EDS instrument design and sampling are available elsewhere (see Statistics Canada 2005).

The 2001 Canadian Census provides the data for the neighbourhoodlevel variables. The census is a reliable source of information for deriv-

5. The Ethnic Diversity Survey excludes residents of collective dwellings (e.g., nursing homes, prisons), Indian reserves, and northern and remote areas. The EDS also excludes persons that declared an Aboriginal origin/identity in the 2001 Census. However, in our study sample, there are 800 respondents who reported Aboriginal origins mixed with other ethnic origins. 
ing a variety of neighbourhood characteristics. Following previous studies, this study defines neighbourhoods as census tracts, which are small areas that represent "natural" neighbourhoods in terms of their socioeconomic and demographic characteristics (Alba et al. 2000; Hou 2006). In Canada, the typical census tract neighbourhood contains approximately 4,000 residents. Using the $20 \%$ sample microdata file (long-form respondents) reduces this number accordingly. In this study, the estimates of the neighbourhood variables are based on an average sample size of about 800 respondents per census tract neighbourhood. Using common geographic identifiers in the census and EDS, the derived neighbourhood data were merged with the individual data. The study sample is restricted to respondents living in neighbourhoods nested in Census Metropolitan Areas (CMA). Statistics Canada (2006) defines a CMA as "one or more adjacent municipalities situated around a major urban core" with at least 100,000 inhabitants. The study excludes cases (amounting to about $2 \%$ of EDS respondents) with missing data on the dependent variables. The study sample consists of 21,150 respondents in 4,027 neighbourhoods in 27 CMAs.

\section{Outcome Variables}

The empirical analysis considers two indicators of self-perceived social integration. These indicators are: (a) sense of belonging to Canada and (b) feelings of discomfort living in the host society. The question for sense of belonging taps whether immigrants feel "at home" in Canada. The respondents were asked: "using a scale of 1 to 5 , where 1 is not strong at all and 5 is very strong, how strong is your sense of belonging to Canada?" In the EDS, this is a distinct question from questions about ethnic or cultural identity. As Table 1 shows, the average level of belonging to Canada is high (4.28), but has considerable variability $(\mathrm{SD}=1.02)$. The second indicator asked: "How often do you feel uncomfortable or out of place in Canada now because of your ethnicity, culture, race, skin colour, language, accent or religion? Is it (1) all of the time, (2) most of the time, (3) some of the time, (4) rarely, or (5) never?" Those who report being uncomfortable also tend to be vulnerable to discrimination (exclusion) based on their ethnic/racial background (Reitz and Banerjee 2009). Among all Canadians, the average level of discomfort is low, falling between rarely and never (the response set is reversed for the variable in the regression analysis).

Both indicators of social integration are ordinal scales and modeled as continuous variables. However, we experimented with alternative modeling strategies, considering that these are discrete and not truly con- 


\section{Table 1. Variable Definitions and Descriptive Statistics for Variables Used in the} Analysis

\author{
Variable \\ Response variables
}

Belonging to Canada

Feel uncomfortable or out of place

Definition/Coding

Mean or $\%$

S.D.

Ordinal scale in 5 levels: $1=$ not strong at all, $5=$ very strong

Ordinal scale in 5 levels: $1=$ never, $5=$ all of the time

Individual characteristics

Immigrant generation

First generation

1.5 generation

Second generation

Third generation or higher

Location

Toronto

Montréal

Vancouver

Other large $\mathrm{CMAs}^{\mathrm{a}}$

Small CMAs

Age

Female

Marital status

Widowed

Divorced or separated

Single

Married

Education

University degree or higher

Some postsecondary education

Secondary education or less

Family income

Lowest income

Low middle income

Middle income

Upper middle income

Income not reported

Highest income

Home language

Racial status

Black

Chinese

South Asian

Other Visible Minorities

Aboriginal

Other European

French

British

$\%$ co-ethnic

Income inequality

Low-income rate

$\%$ with university degrees

$\%$ of non-movers

Population density

First generation immigrants

Immigrants arriving at age 12 or younger

Second generation immigrants

Third or higher order generations

Dummy variable $(1=$ yes, $0=$ no $)$

Dummy variable $(1=$ yes, $0=$ no $)$

Dummy variable $(1=$ yes, $0=$ no $)$

Dummy variable $(1=$ yes, $0=$ no $)$

Reference category

Age in years (range: 15-96)

Dummy variable $(1=$ female, $0=$ male $)$

Dummy variable $(1=$ yes, $0=$ no $)$

Dummy variable $(1=$ yes, $0=$ no $)$

Dummy variable $(1=$ yes, $0=$ no $)$

Reference category

Dummy variable $(1=$ yes, $0=$ no $)$

Dummy variable $(1=$ yes, $0=$ no $)$

Reference category

Dummy variable $(1=<\$ 20,000,0=$ no $)$

Dummy variable $(1=\$ 20,000-39,999,0=$ no $)$

Dummy variable $(1=\$ 40,000-59,999,0=$ no $)$

Dummy variable $(1=\$ 60,000-99,999,0=$ no $)$

Dummy variable $(1=$ yes, $0=$ no $)$

Reference category $(>\$ 100,000)$

Dummy variable $(1=$ home language not

English or French, $0=$ otherwise)

Dummy variable $(1=$ yes, $0=$ no $)$

Dummy variable $(1=$ yes, $0=$ no $)$

Dummy variable $(1=$ yes, $0=$ no $)$

Dummy variable $(1=$ yes, $0=$ no $)$

Dummy variable $(1=$ yes, $0=$ no $)$

Dummy variable $(1=$ yes, $0=$ no $)$

Dummy variable $(1=$ yes, $0=$ no $)$

Reference category

Neighbourhood-level characteristics

$\%$ of own ethnic group (range: (0-0.853) $\quad 0.235 \quad 0.184$

Income inequality (range: $0.704-11.7$ )

Low-income rate (range: 0-0.827)

$\%$ of non-movers (range: $0-0.877$ )

Logged population density (range: 0.200 11.1)

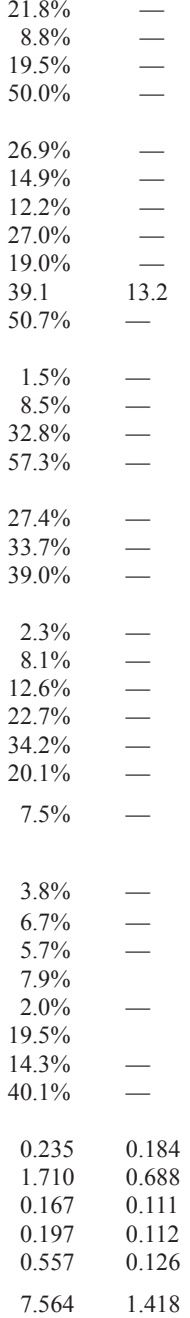

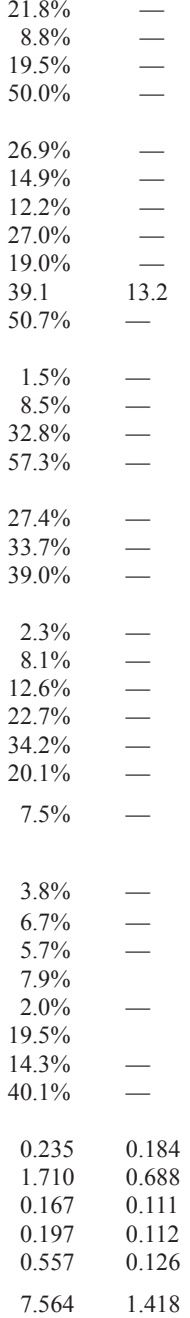

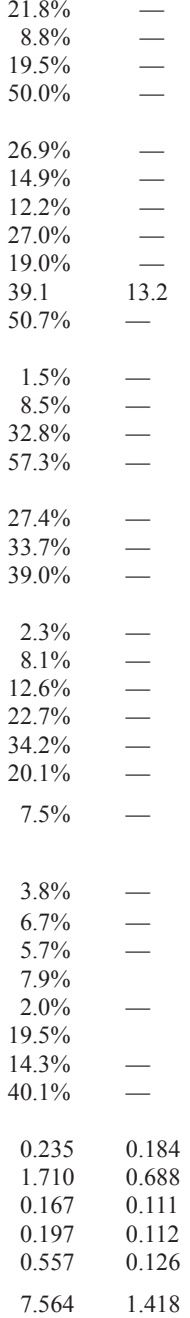

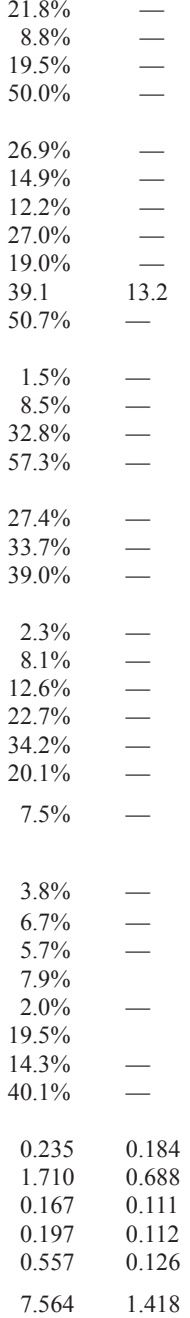

Note: Weighted means and percentages, unweighted N.

Data sources: the 2001 census $20 \%$ sample micro data file and the 2002 Ethnic Diversity Survey.

a Other Large CMAs include Ottawa, Calgary, Edmonton, Winnipeg, and Hamilton. 
tinuous variables. To test whether this is appropriate, we re-estimated the main models (in Tables 2 and 3) with ordered logistic regressions instead. The results from this analysis are similar to the findings from the main models (the results are available from the authors). This demonstrates that it is not inappropriate to treat the outcome variables as continuous variables. We chose to measure them as continuous variables because the regression coefficients in these models have a straightforward (OLS) interpretation.

\section{Independent Variables}

The main independent variable is immigrant generation. Immigrant generation is measured as a 4 level categorical variable: (a) first generation, (b) 1.5 generation, (c) second generation, and (d) third or higher generation Canadians (reference group). The first generation refers to people who immigrated to Canada at age 13 or older. The 1.5 generation refers to immigrants who came to Canada at age 12 or younger. First generation Canadians comprise $21.8 \%$ of people living in CMAs and 1.5 generation Canadians comprise almost $9 \% .{ }^{6}$ The second generation refers to domestic-born Canadians with at least one first generation immigrant parent. Almost $20 \%$ of the study population are second generation Canadians. Third generation Canadians refers to respondents whose parents are both Canadian-born. These people comprise half of the study population.

Ethno-racial status is a well-established indicator of social integration (Reitz and Banerjee 2009). About $83 \%$ of Canadian racial minorities are foreign-born and almost all of them live in CMAs (Statistics Canada 2008). The analysis includes 8 different ethno-racial groups: blacks, Chinese, South Asians, other visible minorities, Aboriginals, French, British (reference group), and other Europeans. These are panethnic groups that have considerable ethnic and cultural variation within them. However, these groups are intended to represent the ethno-racial structure of Canada (vertical mosaic) and not ethnic/racial identities.

The analysis considers several neighbourhood characteristics that could influence the relationship between generational status and social integration. The key neighbourhood characteristic is the residential percentage (concentration) of co-ethnics. This variable is measured as the proportion of co-ethnics in the neighbourhood. The proportion of coethnics ranges between $0-85 \%$. Other neighbourhood characteristics

6. In 2001 , the foreign-born comprised about $18 \%$ of the national population. The foreign-born comprise $30 \%$ of our study sample. The foreign-born are overrepresented in our study sample because our analysis is restricted to metropolitan areas, which is where the vast majority of immigrants live. 
include aggregate socioeconomic status, population turnover, and population density. These contextual variables are common covariates in the neighbourhood effects literature (see Morenoff et al. 2001). Neighbourhood socioeconomic status is defined as income inequality (the coefficient of variation), the percentage of households at the low-income rate (using Statistics Canada cut-offs), and the percentage of residents with a university degree. Neighbourhood turnover is measured according to the percentage of non-movers (past five years). A high amount of neighbourhood turnover could constrain social integration because it could limit the formation of local social networks (Sampson and Graif 2009). Population density is a logarithm of population size per square kilometer.

The regression models also consider several individual and household characteristics that could influence (confound) the relationship between immigrant generation and social integration. The analysis also adjusts for the effects of regional location, age, sex, marital status, education, family income, and home language. Table 1 provides the definitions and descriptive statistics for all selected variables.

\section{Statistical Methods}

To examine the effect of ethno-racial status on the relationship between immigrant generation and integration, the analysis uses standard OLS regression techniques. However, when examining neighbourhood effects, it is possible that endogeneity of residential choices (sorting effects) could bias the regression estimates (Dustmann and Preston 2001). This is particularly true when it comes to the effect of ethnic composition of the neighbourhood. For example, if people with a relatively weak sense of belonging prefer to reside in relatively co-ethnically homogeneous neighbourhoods, then a potentially negative association between sense of belonging and neighbourhood would be overestimated. In other words, self-selection in neighbourhood choices could give the erroneous impression that living in a particular type of neighbourhood (e.g., ethnic enclave) reduces a person's sense of belonging to Canada. Similarly, if people with a weak sense of belonging prefer to avoid such neighbourhoods, then a potentially negative association between sense of belonging and neighbourhood would be underestimated. Hence, it is necessary to correct for sorting effects to avoid incorrectly attributing individual effects to neighbourhood effects.

To address the problem of endogeneity of neighbourhood choice, this study uses an instrumental variable (IV) approach (Dustmann and Preston 2001). The choice of the instrumental variable in this study is based on the notion that the need to remain close to the workplace and 
the desire to remain close to social networks is a constraint on choice of location. To be sure, individuals or households can move into specific neighbourhoods in response to their preference for particular local characteristics, but their mobility is also often constrained across regions. In their study of the relationship between attitudes toward ethnic minorities and local ethnic group composition, Dustmann and Preston (2001) used ethnic composition at the district level (averaging 120,000 residents) as an instrument for ethnic composition at the ward level (averaging 5,000 residents). Their results demonstrate that there is indeed a sorting effect into wards. When ward data of ethnic composition are employed, the relationship between attitudes and contextual effects is biased.

Following Dustmann and Preston (2001), this study uses percent of co-ethnics measured at the municipality level (averaging 110,000 residents) as the instrument for percent of co-ethnics measured at the census tract level. The procedure is equivalent to estimating a two-stage model:

Stage 1: $E_{i j}=a^{*}+b^{*} X_{i}+c^{*} Z_{j}+m^{*} E_{k}+v_{i}$

Stage 2: $Y_{i}=a+b X_{i}+c Z_{j}+m \widehat{E}_{i j}+e_{i}$

where $E_{i j}$ and $E_{k}$ are the proportions of co-ethnics at the neighbourhood and municipality levels, respectively; $X_{\mathrm{i}}$ denotes individual characteristics; $Z_{j}$ refers to neighbourhood variables; $Y_{i}$ is the outcome variable. The parameters $a, b, c, i$, and $m$ (with or without superscripts) are the regression coefficients associated with the corresponding variables; $\hat{E}_{i j}$ is the predicted value from the stage 1 model. The predicted value is a linear combination of their municipality counterparts and other exogenous variables in the stage 2 model. To evaluate the viability (strength) of this instrument, we performed the Cragg-Donald test (Davidson and Schaffer 1993). The test shows that we have a strong instrument.

In the regression models, robust standard errors were computed to account for the cluster effects (correlated errors within neighbourhoods and unequal variances across neighbourhoods) that can arise in multilevel data (Steenbergen and Jones 2002). These models are equivalent to a fixed-intercept model with level-1 covariates within the framework of hierarchical liner models (HLM) (Raudenbush et al. 2000). We first estimated the mean outcome for each neighbourhood adjusted for differences in individual characteristics across neighbourhoods and then regressed the mean outcome on neighbourhood predictors.

In addition, we examined if there is collinearity between ethnic composition and our other selected neighbourhood variables (see Appendix A). Except for income inequality, ethnic composition is significantly correlated with all neighbourhood variables, but the correlations are not strong. The correlations between our selected measures of neigh- 
bourhood SES (income inequality, neighbourhood low-income rate, and percentage of residents with a university degree) are within acceptable limits. There is some overlapping between percent of residents with a university degree and income inequality $(r=.414)$ and between percent of nonmovers and low-income rate $(r=-0.4)$. Otherwise, the correlations between the neighbourhood SES variables, although significant, are low. As a precautionary measure, we also computed variance inflation factors (VIFs) for all explanatory variables in the regression models (the results are available from the authors). As expected, the VIF values are generally low, with only a few coefficients having VIF values greater than 2 . These results suggest that multicollinearity does not pose a serious threat to the efficiency of the regression estimates.

\section{Results}

The objective of this study is to examine the effect of immigrant generation on social integration. To illustrate the complexities of the settlement experience, the analysis proceeds in several stages. The first stage of the analysis examines the effect of immigrant generation on social integration, adjusting for variation in our selected individual variables, except for ethno-racial status. Second, the analysis considers whether ethnoracial status can account for the relationship between immigrant status and social integration. Third, using instrumental variable (IV) regression techniques, the analysis examines whether place of settlement has an influence on the relationship between immigrant generation and social integration. The primary focus is on the ethnic composition of the neighbourhoods where immigrants reside, but other "neighbourhood effects" are also considered. In addition, the study includes separate IV models for whites and visible minorities and considers interactions between immigrant generation and the ethnic composition of neighbourhoods.

Table 2 presents the regressions for sense of belonging to Canada (SBC) on immigrant generation and selected individual and neighbourhood variables. The first column (model) in Table 2 examines whether immigrant generation has a significant effect on SBC, controlling for all selected individual variables, except for ethno-racial status. This model demonstrates that there is a significant relationship between immigrant generation and SBC. Both first and second generation immigrants report a stronger SBC in comparison to third and higher order generation Canadians (reference group). There is a nonsignificant difference between the 1.5 generation and the reference group in SBC. The second model in Table 2 examines whether this relationship is attributable to variation in 
Table 2. Regressions of Sense of Belonging to Canada on Immigrant Generation and Selected Individual-level and Neighbourhood-level Variables

\begin{tabular}{|c|c|c|c|c|}
\hline \multirow{3}{*}{$\begin{array}{l}\text { Independent Variable } \\
\text { Immigrant generation }\end{array}$} & \multicolumn{2}{|c|}{ OLS Regression } & \multicolumn{2}{|c|}{ IV Regression } \\
\hline & \multirow{2}{*}{\multicolumn{2}{|c|}{$b \quad b$}} & \multirow[t]{2}{*}{$b$} & \multirow[t]{2}{*}{ S.E. } \\
\hline & & & & \\
\hline First generation & $0.173 * * *$ & 0.058 & 0.060 & 0.035 \\
\hline 1.5 generation & 0.060 & -0.043 & -0.045 & 0.035 \\
\hline Second generation & $0.080^{* *}$ & -0.021 & -0.025 & 0.026 \\
\hline Third generation or higher ${ }^{\mathrm{a}}$ & & & & \\
\hline \multicolumn{5}{|l|}{ Location } \\
\hline Toronto & -0.005 & -0.025 & -0.021 & 0.032 \\
\hline Montréal & $-0.578 * * *$ & $-0.406 * * *$ & $-0.374 * * *$ & 0.050 \\
\hline Vancouver & $-0.098^{*}$ & $-0.091^{*}$ & -0.072 & 0.043 \\
\hline Other large CMAs & -0.068 & -0.041 & -0.027 & 0.035 \\
\hline Small CMAs ${ }^{\mathrm{a}}$ & & & & \\
\hline Age & $0.012 * * *$ & $0.012 * * *$ & $0.013 * * *$ & 0.001 \\
\hline Female $(1=y e s)$ & $0-062 * *$ & $0.061 * *$ & $0.062 * *$ & 0.022 \\
\hline \multicolumn{5}{|l|}{ Marital status } \\
\hline Widowed & 0.032 & 0.028 & 0.029 & 0.072 \\
\hline Divorced or separated & -0.067 & -0.074 & -0.067 & 0.046 \\
\hline Single & 0.000 & 0.006 & 0.018 & 0.036 \\
\hline Married $^{a}$ & & & & \\
\hline \multicolumn{5}{|l|}{ Education } \\
\hline University degree or higher & $-0.082 * *$ & $-0.072 *$ & -0.058 & 0.030 \\
\hline Some postsecondary education & -0.005 & 0.008 & 0.011 & 0.026 \\
\hline Secondary education or less ${ }^{\mathrm{a}}$ & & & & \\
\hline \multicolumn{5}{|l|}{ Family income } \\
\hline Lowest income & $-0.195 *$ & $-0.197 *$ & $-0.170 *$ & 0.081 \\
\hline Low middle income & $-0.120 *$ & $-0.113 *$ & -0.090 & 0.046 \\
\hline Middle income & $-0.099 *$ & $-0.107 * *$ & $-0.095^{*}$ & 0.039 \\
\hline Upper middle income & $-0.094 * *$ & $-0.096 * *$ & $-0.093 * *$ & 0.033 \\
\hline $\begin{array}{l}\text { Income not reported } \\
\text { Highest income }^{\mathrm{a}}\end{array}$ & $-0.093 * *$ & $-0.086^{* *}$ & -0.071 & 0.032 \\
\hline Home language ( $1=$ non-Eng/French) & $-0.183 * * *$ & $-0.134 * *$ & $-0.125 * *$ & 0.042 \\
\hline Individual-level characteristics & & & & \\
\hline \multicolumn{5}{|l|}{ Racial status } \\
\hline Black & - & 0.011 & 0.024 & 0.062 \\
\hline Chinese & - & $-0.213 * * *$ & $-0.197 * * *$ & 0.048 \\
\hline South Asian & - & $0.155 * * *$ & $0.159 * *$ & 0.049 \\
\hline Other visible minorities & - & -0.023 & -0.10 & 0.062 \\
\hline Aboriginal & - & $-0.270 *$ & -0.264 & 0.145 \\
\hline Other European & - & 0.002 & 0.002 & 0.047 \\
\hline French & - & $-0.535 * * *$ & $-0.530 * * *$ & 0.052 \\
\hline British $^{\mathrm{a}}$ & & & & \\
\hline \multicolumn{5}{|l|}{ Neighbourhood-level characteristics } \\
\hline$\%$ co-ethnic & & & & \\
\hline Income inequality & - & - & $0.030 *$ & 0.015 \\
\hline Low-income rate & - & - & $-0.519 * * *$ & 0.156 \\
\hline$\%$ with university degrees & - & - & $-0.313 *$ & 0.125 \\
\hline$\%$ of non-movers & - & - & -0.029 & 0.106 \\
\hline Population density & - & - & 0.015 & 0.010 \\
\hline Constant & $3.973 * * *$ & $4.042 * * *$ & $4.001 * * *$ & 0.120 \\
\hline R-squared & $0.0670 * * *$ & $0.0940 * * *$ & $0.0978 * * *$ & \\
\hline Individual-level sample size & 21,150 & 21,150 & 21,150 & \\
\hline & & 4,027 & 4,027 & \\
\hline \multirow{3}{*}{\multicolumn{5}{|c|}{$\begin{array}{l}\text { Data sources: The } 2001 \text { census } 20 \% \text { micro data file and the } 2002 \text { Ethnic Diversity Survey } \\
\text { Note: Robust standard errors were estimated for significance tests. }\end{array}$}} \\
\hline & & & & \\
\hline & & & & \\
\hline$* * * 0,001-* * 15$ & & & & \\
\hline
\end{tabular}


ethno-racial status. After introducing ethno-racial status into the model, there are no significant differences in SBC between immigrants and the Canadian-born. This demonstrates that the differences observed in the previous model are indeed attributable to variation in ethno-racial status. In other words, immigrant generation does not have an independent effect on SBC, net of differences in ethno-racial status.

As the IV regression shows (see third column/model), neighbourhood effects have a nonsignificant influence on the relationship between immigrant generation and sense of belonging to Canada. In particular, the ethnic composition of the neighbourhood has a nonsignificant effect - whether an immigrant lives mostly among co-ethnics or in an ethnically heterogeneous neighbourhood is inconsequential for their SBC. However, neighbourhood SES does have some significant effects on SBC, but these are inconsistent and difficult to interpret. As would be expected, SBC decreases as the low-income rate of the neighbourhood increases, which is likely a proxy for the disenfranchisement of the poor. What is perplexing is that income inequality in the neighbourhood increases SBC and percent of persons with a university degree decreases SBC. There is no straightforward interpretation for these latter results. Further research is needed to explain these findings.

Table 3 presents the regressions for feeling uncomfortable or out of place on immigrant generation and selected individual and neighbourhood variables. This table follows a similar modeling strategy as in Table 2 . The first model shows that immigrant generation has a significant effect on feelings of discomfort living in the host society because of racial status, skin colour, culture, and/or other markers of difference from the majority group. First generation immigrants report higher levels of discomfort than third generation Canadians. In contrast, second generation Canadians report comparatively lower levels of discomfort. There is no significant difference between the 1.5 and third generations in feelings of discomfort. The second model in Table 3 considers whether these generational differences are attributable to variation in ethno-racial status. While introducing ethno-racial status into the model changes the size of the coefficients, it does not account for the relationship between immigrant generation and feelings of discomfort. The magnitude of the difference between the first and third generation deceases, which suggests that ethno-racial status is indeed relevant. In addition, a significant difference between the 1.5 and third generation emerges after controlling for ethnoracial status. In this model, the 1.5 generation has comparatively lesser feelings of discomfort.

Again, the ethnic composition of neighbourhoods and other neighbourhood effects do not influence generational differences in feelings of 
Table 3. Regressions of Feeling out of Place on Immigrant Generation and Selected Individual-level and Neighbourhood-level Variables

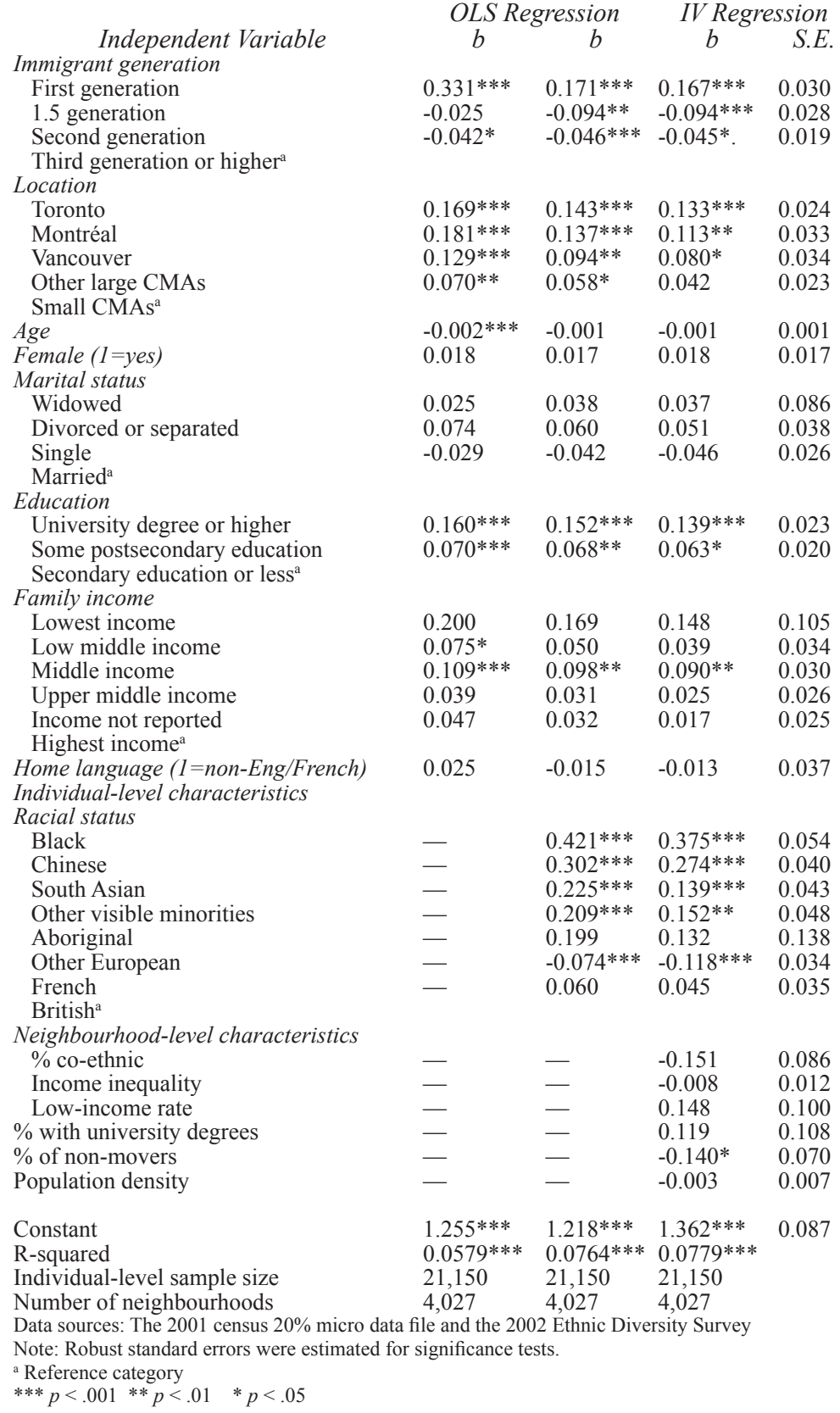


discomfort. However, neighbourhood turnover (i.e., percent of nonmovers) has a significant effect on people's feelings of discomfort. This finding demonstrates that neighbourhood turnover has a detrimental (negative) effect on perceptions of fitting in.

For SBC, the effect of racial status is inconsistent, but significant for some racial groups. The IV model in Table 2 shows that SBC is lower among Chinese and French Canadians than it is among British-origin Canadians. While this could correspond to their marginalized status in Canadian society, other racial minorities (e.g., blacks, Aboriginals) are similar to British-origin Canadians in SBC and South Asian Canadians report a higher SBC. To some extent, these findings could reflect the culturally subjective nature of SBC, rather than external circumstances (e.g., discrimination) that are germane to all minority groups. However, it is clear from our findings that racial status is an impediment to feeling comfortable in the host society. As Table 3 shows, all racial minorities report higher levels of discomfort than the majority group.

Given the influence of racial status on social integration, we re-ran the IV analysis in Tables 2 and 3 for whites and racial minorities separately. This reanalysis takes into consideration interaction effects between immigrant generation and racial status on social integration. The rationale for this reanalysis is the possibility that a negative (or positive) effect among racial minorities in combination with a positive (or negative) effect among whites could cancel one another out in the general findings presented in the earlier tables. In other words, the findings for the general population could conceal subpopulation differences in the effects of immigrant generation on social integration. Table 4 presents the results of the reanalysis. For both whites and racial minorities, the relationship between immigrant generation and SBC is nonsignificant, but the reanalysis brings into relief interracial differences in discomfort. For both subpopulations, there are stronger feelings of discomfort among first generation immigrants, but this generational effect is stronger for racial minorities. Compared to third generation whites, 1.5 and second generation whites feel more comfortable or less out of place. There are no other generational differences among racial minorities.

Table 5 presents the IV models that consider interaction effects between immigrant generation and co-ethnic concentration. These models are built upon the IV models in Tables 2 and 3. The purpose of this supplementary analysis is to examine if the effect of immigrant generation changes depending upon the level of co-ethnic concentration. For ease of interpretation, these findings are graphed in Figure 1.

For both outcome variables, the change in R-squared is significant $(p<.01)$, suggesting that there are significant interactions between immi- 
Table 4. Instrumental Variable Regressions of Sense of Belonging to Canada and Feeling out of Place on Immigrant Generation: Whites and Racial Minorities

\section{Independent Variable}

Immigrant generation

First generation

1.5 generation

Second generation

Third generation or higher ${ }^{\mathrm{a}}$

Location

Toronto

Montréal

Vancouver

Other large CMAs

Small CMAs ${ }^{\mathrm{a}}$

Age

Female ( $1=$ yes $)$

Marital status

Widowed

Divorced or separated

Single

Married

Education

University degree or higher

Some postsecondary education

Secondary education or less ${ }^{\mathrm{a}}$

Family income

Lowest income

Low middle income

Middle income

Upper middle income

Income not reported

Highest income $^{\mathrm{a}}$

Home language ( $1=$ non-Eng/French)

Individual-level characteristics

Racial status

Black

Chinese $^{\mathrm{a}}$

South Asian

Other visible minorities

Other European

French

British $^{\mathrm{a}}$

Neighbourhood-level characteristics

$\%$ co-ethnic

Income inequality

Low-income rate

$\%$ with university degrees

$\%$ of non-movers

Population density

\section{Constant}

R-squared

Individual-level sample size

Number of neighbourhoods

Data sources: The 2001 census $20 \%$ micro da

Note: Robust standar

${ }^{a}$ Reference category

$* * * p<.001 * * p<.01 \quad * p<.05$

\section{Belonging to Canada Feeling out of Place} $\begin{array}{lll}\text { Whites } & \text { Racial } \\ \text { Minorities }\end{array}$ Whites $\begin{gathered}\text { Racial } \\ \text { Minorities }\end{gathered}$

$\begin{array}{lrrl}-0.045 & 0.048 & 0.102 * * & 0.433 * * * \\ -0.043 & -0.075 & -0.089 * * & 0.083 \\ -0.003 & -0.170 & -0.048 * & 0.127\end{array}$

$\begin{array}{llll}0.017 & -0.054 & 0.140 * * * & 0.077\end{array}$

$\begin{array}{llll}-0.444 * * * & -0.093 & 0.165 * * * & -0.084\end{array}$

$\begin{array}{llll}-0.042 & -0.045 & 0.086 * & 0.048\end{array}$

$\begin{array}{llll}-0.021 & -0.038 & 0.037 & 0.006\end{array}$

$\begin{array}{llll}0.012 * * * & 0.015 * * * & 0.000 & -0.003\end{array}$

$\begin{array}{llll}0.085 * * & -0.005 & -0.004 & 0.086 * *\end{array}$

$\begin{array}{llll}0.085 & -0.135 & -0.216 & -0.315^{*}\end{array}$

$\begin{array}{llll}-0.065 & -0.105 & -0.109 & -0.019\end{array}$

$\begin{array}{llll}0.034 & 0.025 & 0.029 & -0.029\end{array}$

$\begin{array}{llll}-0.085 * & 0.010 & 0.112 * * * & 0.213 * * * \\ -0.003 & 0.059 & 0.052 * & 0.097 *\end{array}$

$\begin{array}{llll}-0.242 & -0.044 & 0.045 & 0.037\end{array}$

$\begin{array}{llll}-0.122 * & 0.031 & 0.012 & 0.060\end{array}$

$\begin{array}{llll}-0.102 * & -0.023 & 0.052 & 0.168 * *\end{array}$

$\begin{array}{llll}-0.101 * * & -0.009 & 0.040 & -0.048\end{array}$

$\begin{array}{llll}-0.071 & -0.011 & -0.003 & 0.024\end{array}$

$\begin{array}{llll}0.007 & -0.175 * * * & 0.088 & -0.037\end{array}$

— $0.185^{* * *} \quad-\quad 0.087$

$\begin{array}{cccc}- & 0.367 * * * & - & -0.105^{*} \\ - & 0.154 * & - & -0.193 * * \\ -0.007 & - & -0.095^{* *} & - \\ -0.481 * * * & - & 0.032 & -\end{array}$

$\begin{array}{lrrr}-0.065 & 0.021 & -0.065 & -0.558^{*} \\ 0.034 & 0.020 & 0.000 & -0.038 \\ -0.908^{* * *} & 0.105 & 0.220 & 0.212 \\ -0.394 * * & -0.195 & 0.078 & 0.211 \\ -0.222 & 0.301 & -0.019 & -0.251 \\ 0.024 * & -0.018 & 0.000 & -0.016\end{array}$

$\begin{array}{llll}4.143 * * * & 3.628 * * * & 1.215 * * * & 1.761 * * * \\ 0.113 * * * & 0.084 * * * & 0.026 * * * & 0.052 * * * \\ 13,968 & 6,926 & 13,968 & 6,926 \\ 3,670 & 2,459 & 3,670 & 2,459\end{array}$


Table 5. Interaction Effects of Immigrant Generation and Percent of Own Ethnic Group on Sense of Belonging to Canada and Feeling out of Place

Independent Variable

Immigrant generation

First generation

1.5 generation

Second generation

Third generation or higher

Neighbourhood-level characteristics

$\%$ co-ethnic

Interactions

1st generation $\mathrm{x}$ ethnic enclave

1.5 generation $\mathrm{x}$ ethnic enclave

2nd generation $x$ ethnic enclave

Constant

R-squared

Individual-level sample size

Number of neighbourhoods

Data sources: the 2001 census $20 \%$ sample micro data

Note: The models also include all other variables in Table 2.

${ }^{a}$ Reference category. $* * * p<.001 ; * * p<.01 ; * p<.05$

Figure 1. Interaction Effects of Immigrant Generation and Co-ethnic Residence

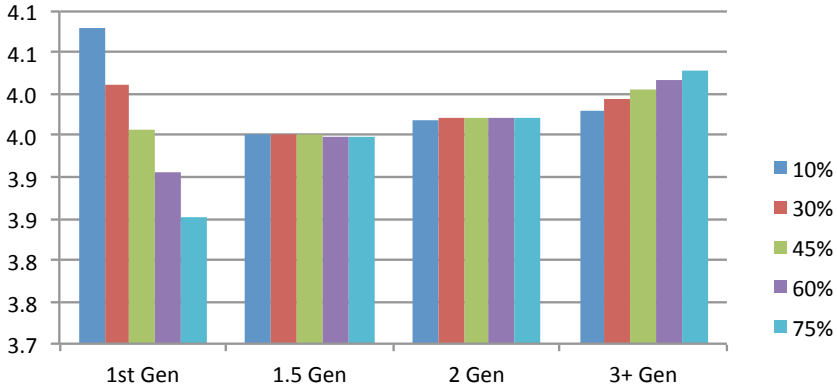

Sense of belonging to Canada by level of co-ethnics

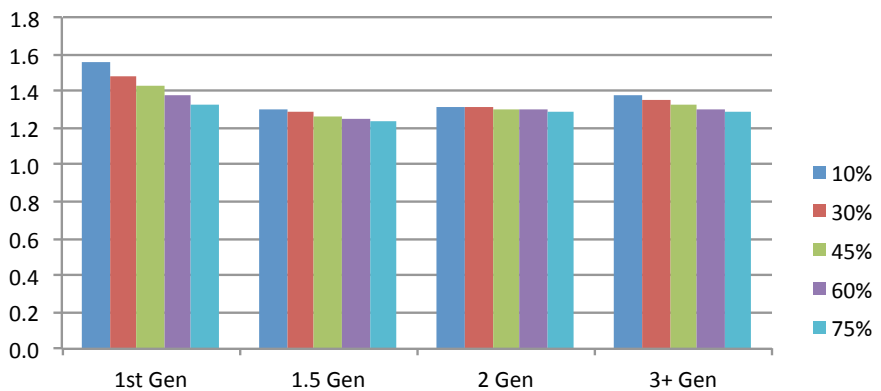

Feeling out of place bv level of co-ethnics

Note: Regression estimates are obtained from Tables 2, 3 and 5. 
grant generation and co-ethnic concentration. Because computing interaction effects involves both "main effects" and "interaction effects," the interaction effects can be more clearly seen in Figure 1. For SBC, the effect of co-ethnic concentration appears to be largely a phenomenon among first generation Canadians. Among first generation Canadians, SBC tends to decrease as the proportion of co-ethnics increases. This suggests that co-ethnic concentration (e.g., ethnic enclaves) could be a barrier to SBC among first generation Canadians. There are no significant interaction effects for the 1.5 or second generations. For 1.5 and second generation Canadians, SBC appears to be stable across neighbourhoods with differing proportions of co-ethnics. For the third or higher generations, the trend appears to be reversed, although it is not as dramatic as that of the first generation.

For feeling uncomfortable, the interaction effects are weak. However, it also appears to be a first generation phenomenon. Among this generation, the frequency of feeling uncomfortable decreases as concentrations of co-ethnics rises. This implies that living in an ethnic enclave could protect first generation Canadians from feeling out of place in Canada, albeit to a minor extent.

\section{Conclusion}

This study examined differences in social integration between generational cohorts of immigrants, focusing on two outcomes: sense of belonging to Canada and feeling uncomfortable or out of place in Canada because of differences (e.g., racial status, culture, skin colour) from the core/majority group. The empirical analysis unpacked this relationship in terms of the context of the settlement experience, looking at ethno-racial differences and neighbourhood effects. The main conclusion is that the relationship between immigrant generation and social integration is not straightforward, but depends on a combination of factors, including intersections between generational status, racial status, and neighbourhood characteristics.

For sense of belonging to Canada (SBC) there are some generational effects, but these correspond to differences in racial status. These results do not appear to offer support for an independent generational effect on SBC. In other words, SBC does not improve or decline across successive cohorts of immigrants. The multilevel regression analysis also demonstrates that spatial assimilation or residential segregation does not influence generational differences in SBC, although neighbourhood socioeconomic status has some significant effects. For instance, living in 
a low-income neighbourhood, regardless of individual SES, significantly reduces a person's SBC. The results for feeling uncomfortable in the host society were more consistent with our expectations. We observed significant generational effects, after adjusting for individual characteristics, but the neighbourhood effects are inconsequential. However, the results indicate that feelings of discomfort tend to recede across generations, which supports the notion of intergenerational progress.

There is also a significant interaction between immigrant generation and racial status that influences feelings of discomfort, but not SBC. For feelings of discomfort, all first generation immigrants have lower subjective well-being than other Canadians. This effect is much stronger for racial minorities than it is for whites. This suggests that racial status is a potential barrier to social integration. Despite multiculturalism, first generation immigrants appear to encounter greater difficulties in feeling "at home" in Canada because of their skin colour, religion, or ethnic status. While this is not evidence for an outright lack of acceptance within their host communities, it does indicate that these people face unique challenges in their interactions with other Canadians and adaptation to Canadian social life. That said, our findings demonstrate that immigrants become more comfortable in the host society across generations, and it seems that a portion of their initial discomfort could associate with their newcomer status and socialization in a foreign culture.

However, our findings also demonstrate the contingent nature of residential concentration or living largely among co-ethnics. Though neighbourhood effects do not explain generational differences, the aggregate results conceal important interaction effects, which cautions us against making generalizations that fail to account for the complexities of the integration process. Among first generation immigrants, there is a linear relationship between concentration of co-ethnics and sense of belonging to Canada and feelings of discomfort. With spatial assimilation, SBC becomes stronger among the first generation. The high proportion of racial minorities among the first generation is not a trivial matter, and other Canadian research suggests that concentration of recent immigrants in ethnic enclaves could be a barrier to their integration (Murdie and Ghosh 2010). Our findings also suggest a possible protective effect of living in an ethnic enclave, as feelings of discomfort are the lowest among immigrants living among higher concentrations of co-ethnics, although it is important not to overstate the size of the effect, which is small.

The literature demonstrates that immigrants fare less well than the Canadian-born on life satisfaction (Houle and Schellenberg 2010). There is also evidence of intergenerational decline - the 1.5 generation (child immigrants) and second generation tend to have less favourable per- 
ceptions of their relationship with the host society than first generation immigrants (Gans 1992; Rumbaut 1994). For example, perceptions of discrimination are more common among the Canadian-born children of racial minority immigrants than among their parents (Reitz and Banerjee 2009). This suggests that there is a growing gap in the social exclusion of immigrants, especially those from non-European sending countries. Though this remains an important concern, our findings offer a more positive conclusion in regards to the social integration of immigrants and their children. At least, these people fare no worse than the Canadianborn in their sense of belonging to Canada and their feelings of discomfort living in the host society fades across generations. This suggests that most immigrants adopt Canada as their "home" and successfully adapt to Canadian social life over time.

\section{REFERENCES}

Aydemir, A., Chen, W. and Corak, M. 2008. Intergenerational Educational Mobility among the Children of Canadian Immigrants. Ottawa: Statistics Canada.

Alba, R.D., J.R. Logan, and B.J. Stults. 2000. The changing neighborhood contexts of the immigrant metropolis. Social Forces 79(2):587-621.

Alba, R. and V. Nee. 1997. Rethinking assimilation theory for a new era of immigration. International Migration Review 31(4):826-847.

Banting, K.G., T.J. Courchene, and F.L. Seidle, eds. 2007. Belonging? Diversity, Recognition, and Shared Citizenship in Canada. Montréal: Institute for Research on Public Policy.

Bartley, A. and P. Spoonley. 2008. Intergenerational transnationalism: 1.5 generation Asian migrants in New Zealand. Intergenerational Migration 46(4):63-84.

Berry, J.W., U. Kim, T. Minde, and D. Mok. 1987. Comparative studies of acculturative stress. International Migration Review 21(3):491-511.

Böhlmark, A. 2009. Integration of childhood immigrants in the short and long run — Swedish evidence. International Migration Review 43(2):387-409.

Bolt, G., A.S. Özüekren, and D. Phillips. 2010. Linking integration and residential segregation. Journal of Ethnic and Migration Studies 36(2):169-186.

Boyd, M. 2002. Educational attainments of immigrant offspring: success of segmented assimilation? International Migration Review 36(4):1037-1060.

Brown, S.K. 2006. Structural assimilation revisited: Mexican-origin nativity and cross-ethnic primary ties. Social Forces 85(1):75-92. 
Burton, P. and S. Phipps. 2010. The well-being of immigrant children and parents in Canada. Working Paper No. 2010-09. Dalhousie University, Department of Economics.

Chow, H.P.H. 2007. Sense of belonging and life satisfaction among Hong Kong adolescent immigrants in Canada. Journal of Ethnic and Migration Studies 33(3):511-520.

Danico, M.Y. 2004. The 1.5 Generation: Becoming Korean American In Hawaii. Honolulu: University of Hawaii Press.

Davidson, R. and J.G. Schaffer. 1993. Estimation and Inference in Econometrics. Oxford: Oxford University Press.

Deng, J. and G.J. Walker. 2007. Chinese acculturation measurement. Canadian Ethnic Studies 39(1/2):187-217.

Dustmann, C. and I. Preston. 2001. Attitudes to ethnic minorities, ethnic context, and location decisions. The Economic Journal 111(470):353-73.

Fong, E. and R. Wilkes. 2003. Racial and ethnic residential patterns in Canada. Sociological Forum 18(4):577-602.

Gans, H. 1992. Second-generation decline: Scenarios for the economic and ethnic futures of the post-1965 American immigrants. Ethnic and Racial Studies 15(2):173-192. 1997. Toward a reconciliation of "assimilation" and "pluralism": The interplay of acculturation and ethnic retention. International Migration Review 31(4):875-891.

Gordon, M.M. 1964. Assimilation in American Life. New York: Oxford University Press.

Hirschman, C. 1994. Problems and prospects of studying immigrant adaptation from the 1990 population census: From generational comparisons to the process of "becoming American." International Migration Review 28(4):690-713.

Hou, F. 2006. Spatial assimilation of racial minorities in Canada's immigrant gateway cities. Urban Studies 43(7):1191-1213.

Houle, R. and Grant Schellenberg. 2010. New immigrants' assessments of their life in Canada. (Catalogue no. 11F0019M - No. 322). Statistics Canada, Social Analysis Division. Ottawa: Ministry of Industry.

Kong, L. 1999. Globalisation and Singaporean transmigration: Re-imagining and negotiating national identity. Political Geography 18(5):563-589.

Lee, S. and M. Boyd. 2008. Marrying out: comparing the marital and social integration of Asians in the us and Canada. Social Science Research 37(1):311-329.

Massey, D.S. 1985. Ethnic residential segregation: A theoretical synthesis and empirical review. Sociology and Social Research 69(3):315-350. 1990. American apartheid: Segregation and the making of the underclass. American Journal of Sociology 96(2):329-357. 
Massey, D.S. and N.A. Denton. 1987. Trends in the residential segregation of Blacks, Hispanics, and Asians: 1970-1980. American Sociological Review 52(6):802-825.

Morenoff, J.D., R.J. Sampson, and S.W. Raudenbush. 2001. Neighborhood inequality, collective efficacy, and the spatial dynamics of urban violence. Criminology 39(3):517-560.

Murdie, R. and S. Ghosh. 2010. Does spatial concentration always mean a lack of integration? Exploring ethnic concentration and integration in Toronto. Journal of Ethnic and Migration Studies 36(2):293-311.

Musterd, S. 2003. Segregation and integration: A contested relationship. Journal of Ethnic and Migration Studies 29(4):623-641.

Oropesa, R.S. and N.S. Landale. 1997. In search of the new second generation: Alternative strategies for identifying second generation children and understanding their acquisition of English. Sociological Perspectives 40(3):429-455.

Pagnini, D.L. and S.P. Morgan. 1990. Intermarriage and social distance among U.S. immigrants at the turn of the century. American Journal of Sociology 96(2):405-432.

Portes, A. and M. Zhou. 1993. The new second generation: Segmented assimilation and its variants. Annals of the American Academy of Political and Social Science 530:74-96.

Raudenbush, S.W., A.S. Bryk, Y.F. Cheong, and R.T. Congdon. 2000. HLM5 Hierarchical Linear and Nonlinear Modeling. Lincolnwood: Scientific Software International.

Ray, B. and V. Preston. 2009. Geographies of discrimination: Variations in perceived discomfort and discrimination in Canada's gateway cities. Journal of Immigrant and Refugee Studies 7(3):228-249.

Reitz, J.G. and R. Banerjee. 2007. Racial inequality, social cohesion, and policy issues in Canada. Pp. 498-545 in K. Banting, T.J. Courchene, and F.L. Seidle, eds., Belonging? Diversity, Recognition, and Shared Citizenship in Canada Montréal, PQ: Institute for Research on Public Policy. 2009. Racial Inequality and Social Integration. Pp. 123-155 in J.R. Reitz, R. Breton, K. Kisiel Dion, and K.L. Dion, eds., Multiculturalism and Social Cohesion: Potentials and Challenges of Diversity. New York: Springer.

Rumbaut, R.G. 1994. The crucible within: Ethnic identity, self-esteem, and segmented assimilation among children of immigrants. International Migration Review 28(4):748-794.

2004. Ages, life stages, and generational cohorts: Decomposing the immigrant first and second generations in the United States. International Migration Review 38(3):1160-1205.

Sampson, R.J. and C. Graif. 2009. Neighborhood social capital as differential social organization: Resident and leadership dimensions. American Behavioral Scientist 52(11):1579-1605. 
Sampson, R.J., J.D. Morenoff, and T. Gannon-Rowley. 2002. Assessing "neighborhood-effects": Social processes and new directions in research. Annual Review of Sociology 28:443-478

Schellenberg, G. 2004. Perceptions of Canadians: A sense of belonging, confidence, and trust. Canadian Social Trends (Winter Issue):16-21.

Soroka, S., R. Johnston, and K. Banting. 2007. Ties that bind? Social cohesion and diversity in Canada. Pp. 561-600 in K. Banting, T. J. Courchene, and F. L. Seidle, eds., Belonging? Diversity, Recognition, and Shared Citizenship in Canada. Montréal, PQ: Institute for Research on Public Policy.

Statistics Canada. 2003. Ethnic Diversity Survey. The Daily (September 29):2-5. - 2005. Ethnic Diversity Survey - User Guide. Ottawa: Ministry of Industry. 2006. Canada Year Book 2006. Ottawa: Ministry of Industry. 2007. Immigration and citizenship. Published Online: http://www12. statcan.gc.ca/census-recensement/2006/rt-td/immcit-eng.cfm. Accessed December 12, 2011.

2008. Canada Year Book 2008. Ottawa: Ministry of Industry.

Steenbergen, M. and B. Jones. 2002. Modeling multilevel data structure. American Journal of Political Science 46(1):218-237.

Thomas, K.J.A. 2010. Household context, generational status, and English proficiency among the children of African immigrants in the United States. International Migration Review 44(1):142-172.

Vermeulen, H. 2010. Segmented assimilation and cross-national comparative research on the integration of immigrants and their children. Ethnic and Racial Studies 33(7):1214-1230.

Vohra, N. and J. Adair. 2000. Life satisfaction among Indian immigrants in Canada. Psychology and Developing Societies 12(2):109-138.

Waters, M.C. and K. Eschbach. 1995. Immigration and ethnic and racial inequality in the United States. Annual Review of Sociology 21:419-446.

Waters, M.C. and T.R. Jiménez. 2005. Assessing immigrant assimilation: New empirical and theoretical challenges. Annual Review of Sociology 31:105-125.

Wu, Z., F. Hou, and C.M. Schimmele. 2011. Racial diversity and sense of belonging in urban neighborhoods. City \& Community 10(4):373-392.

Zheng Wu is Professor of Sociology and Director of the Population Research Group at the University of Victoria. He is also affiliated with University of Victoria's Centre on Aging, University of Washington's Centre for Studies in Demography and Ecology, and Xi' an Jiaotong University's Institute of Population and Development Studies. His research interests reach across numerous sociodemographic topics, with long-standing interest in family demography, immigration, aging, and population health.

Christoph M. Schimmele is a doctoral candidate in the Department of Sociology at the University of Victoria. His primary research interest is on social differences in health and illness. 
Feng Hou is a senior researcher with Statistics Canada and an adjunct professor of Sociology at the University of Victoria. His research interests are the socioeconomic integration of immigrants and the second generation, dynamics of social diversity, and community contextual effects. His recent publication "Intermarriage and status-caste exchange in Canada and the United States" is published in Ethnic and Racial Studies 2012. 